\title{
Distribution law of rice pollen in the wind field of small UAV
}

\author{
Li J iyu ${ }^{1,2}$, Yubin Lan $^{1,2^{*}}$, Wang J ianwei ${ }^{1,2}$, Chen Shengde ${ }^{1,2}$, Huang Cong ${ }^{1,2}$, \\ Liu Qi ${ }^{1,2}$, Liang Qiuping ${ }^{3}$
}

\author{
(1. College of Engineering, South China Agricultural University, Guangzhou 510642, China; \\ 2. International Laboratory of Agricultural Aviation Pesticide Spraying Technology, Guangzhou 510642, China; \\ 3. College of Foreign Studies, South China Agricultural University, Guangzhou 510642, China)
}

\begin{abstract}
The wind field produced by the rotor-wing UAV has a significant impact on the distribution of rice pollen, which directly influences hybrid rice breeding. This research aimed to explore the distribution law of rice pollen in the wind field of small UAV. Aviation Beidou Positioning System UB351 positions all sampling nodes for precise corresponding coordinates and spacing information, and draws UVA's flying trajectories, thus providing accurate data for tests. Wireless sensor network measurement system was used to study the three-direction wind field produced by the rotor-wing UAV under various experimental factors and acquires wind field width and wind speed, and the data were compared with the area ratio and width of pollen distribution. Test of univariate normality was conducted through Shapiro-Wilk test and Kolmogorov-Smimov test. In order to figure out the appropriate flight speed for UAV's pollination under pollen distribution law, it is also necessary to perform analysis of variances on regression model. The comparison of wind speed in longitudinal $(X)$ and lateral $(Y)$ direction show that as the major force of the horizontal wind field produced by the rotor-wing UAV, the wind from $Y$-direction forms the widest wind field. Moreover, flight speed mainly influences wind field width. To be specific, the width of horizontal wind field decreases as flight speed increases. Meanwhile, UAV flight speed also exerts significant impact on vertical wind field. Both the pollen distribution width of more than 5 pollen grains and the area ratio reached the maximum when the UAV flight was at $4.53 \mathrm{~m} / \mathrm{s}$, which was the most favorable speed to pollination. In addition, pollen quantity is closely associated with both horizontal and vertical wind field. With comparison of the pollen quantity of sampling nodes, it was found that the wind field produced by the rotor-wing UAV exerted asymmetrical impact on pollen distribution. Q-Q plot of SPSS verifies that pollen distribution is against normal distribution. The establishment of a multiple linear regression model of pollen distribution and wind speed in three directions indicates that pollen distribution quantity only shares positive linear relation with the wind field in $X$-direction. These findings provide a theoretical guidance for rice pollination by using agricultural UAVs.
\end{abstract}

Keywords: UAV, pollen distribution, pollination, wind field distribution, rice breeding

DOI: $10.25165 /$ j.ijabe.20171004.3103

Citation: Li J Y, Lan Y B, Wang J W, Chen S D, Huang C, Liu Q, et al. Distribution law of rice pollen in the wind field of small UAV. Int J Agric \& Biol Eng, 2017; 10(4): 32-40.

\section{Introduction}

As a technology to increase grain production, the promotion and application of hybrid rice will be the most

Received date: 2016-12-14 Accepted date: 2017-01-07

Biographies: Li Jiyu, PhD, Associate Professor, research interest: agricultural aviation application, Email: lijiyuscau@qq.com; Wang Jianwei, MS, research interest: agricultural aviation application, Email: 745711661@qq.com; Chen Shengde, PhD candidate, research interest: agricultural aviation application, Email: 1163145190@qq.com; Huang Cong, Postgraduate, research interests: agricultural aviation, Email: 1339492499@qq.com; Liu Qi, Postgraduate, research interest: agricultural aviation effective way to address world food crisis ${ }^{[1]}$. Breeding, seed production, raising seedlings and transplanting are the major processes of hybrid rice production. Seed production is the essential part of hybrid rice production, which is then determined by pollination ${ }^{[2]}$. Because of

application, Email: 467061676@qq.com; Liang Qiuping, postgraduate, research interest: agricultural aviation application, Email: cupidhuaidan@163.com.

*Corresponding author: Yubin Lan, PhD, Professor, research interest: agricultural aviation application. International Laboratory of Agricultural Aviation Pesticide Spraying Technology (ILAAPST), South China Agricultural University, Guangzhou 510642, China. Email: ylan@scau.edu.cn. 
not being a strict self-pollination crop, rice has a slim chance of natural pollination, ranging from $0.2 \%$ to $4 \%$ with a maximum of $5 \%^{[3]}$. Rice flowers for about 1.5-2.0 h, from 10:00 a.m. to 12:00 a.m. Furthermore, it pollinates 3-4 times a day, each within $30 \mathrm{~min}$, and lasts for 10-12 $\mathrm{d}^{[4]}$. Since hybrid rice pollination is demanding in technology, accuracy and time, high-yield and high quality hybrid rice seeds must be produced by cross-pollination. Cross-pollination should be assisted by artificial supplementary pollination to ensure well-balanced seed setting. Hand pollination and mechanical pollination are two popular artificial supplementary pollination methods. Hand pollination is widely applied in areas with abundant labor force but low mechanization level. Though it is simple to operate with promising outcomes ${ }^{[5]}$, this method is characterized by great labor intensity, low efficiency and not applicable to large-scale seed production. Mechanical pollination can be further divided into collision pollination and pneumatic pollination. The former one is about shaking off the pollen from the male plant to the female one through direct collision ${ }^{[6]}$. It tends to hurt the plant and performs poorly in realizing uniform pollination ${ }^{[7]}$. Owing to its merits of long-distance spraying of male parent pollen without hurting the plant, pneumatic pollination enjoys rapid development and extensive use. $\mathrm{Li}$ et al. ${ }^{[8-10]}$ select the operation parameters for supplementary pollination of hybrid rice by using a small rotor-wing unmanned helicopter, and explore the distribution law of canopy wind field during rotor-wing UAV's pollination. $\mathrm{Hu}$ et al. ${ }^{[11]}$ designed a wireless wind speed sensor network measurement system for unmanned helicopter. Wang et al. ${ }^{[12]}$ studied the impact of airflow speed on pollen distribution in the process of hybrid rice seed production while Fang et al. ${ }^{[13]}$ investigated the impact of bottom blowing airflow speed on the distribution of hybrid rice pollen. Wu et al. ${ }^{[14]}$ evaluated the performance of unmanned helicopter for agricultural plant protection in supplementing hybrid rice pollination and attempted to figure out the optimum planting row ratio of male and female parent rice.

Small UAVs are enjoying increasing popularity in agriculture, especially in supplementary pollination for hybrid rice seed production. However, concrete progress in how UAV's wind field parameters affect rice pollen distribution is still unavailable. To this end, this study explores the impact of various UAV's wind field parameters on rice pollen distribution in natural environment and figures out the width of pollen distribution and valid interval value at varying wind speeds in the hope of providing theoretical guidance and data support to improve hybrid rice pollination and operating efficiency.

\section{Materials and methods}

\subsection{Materials and devices}

2.1.1 Materials and devices for outdoor UAV's pollination tests

The 80-2 gasoline-driven single-rotor UAV (Hunan Dafang Plant Protection Co., Ltd) serves these tests as shown in Figure 1, its main performance indexes are shown in Table 1.

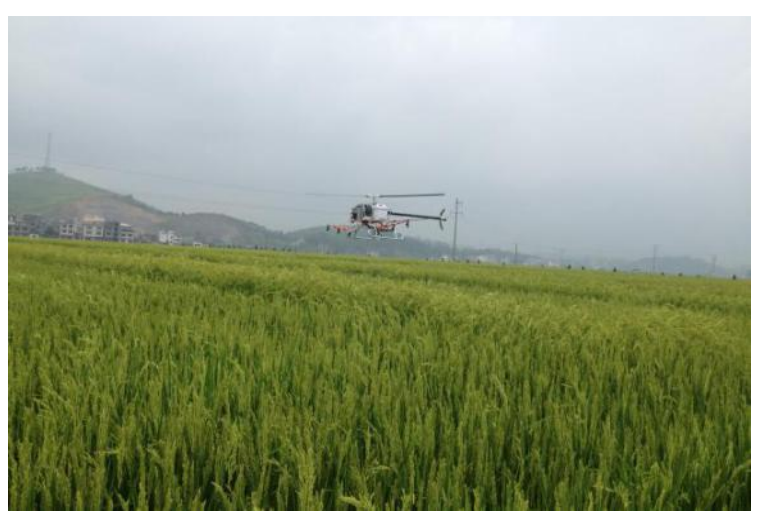

Figure 1 Test field for UAV's pollination

Table 1 Main performance indexes of UAV

\begin{tabular}{|c|c|c|c|c|c|}
\hline Main Parameters & Type & $\begin{array}{c}\text { Size } \\
\text { (length } \times \text { width } \times \text { height })\end{array}$ & Diameter of main rotor/tail & $\begin{array}{l}\text { Flight speed } \\
\qquad / \mathrm{m}^{-1} \mathrm{~s}^{-1}\end{array}$ & $\begin{array}{c}\text { Flight altitude } \\
\text { /m }\end{array}$ \\
\hline Specifications and Figures & $\begin{array}{c}\text { 80-2 single-rotor } \\
\text { gasoline-driven UAV }\end{array}$ & $1760 \mathrm{~mm} \times 580 \mathrm{~mm} \times 750 \mathrm{~mm}$ & $2080 \mathrm{~mm} / 350 \mathrm{~mm}$ & $0-8$ & $0.5-3$ \\
\hline
\end{tabular}

Beidou Positioning System UB351 used in these tests is characterized by RTK differential positioning with a plane accuracy of $1 \mathrm{~cm}+0.5 \mathrm{ppm}$ and an elevation accuracy of $2 \mathrm{~cm}+1 \mathrm{ppm}$. The authors hold the mobile station to position every sampling node and accurately record their corresponding coordinates and spacing 
information. Beidou system on-board the UAV draws operating trajectory, against which the relation between actual operating trajectory and sampling node is observed.

Wireless wind speed sensor network measurement system for unmanned helicopter ${ }^{[11]}$ was used, consisting of paddlewheel wind speed sensor and wireless wind speed sensor. The former one measured the three-direction wind speed at every sampling node during pollination, detecting speed from 0 to $45 \mathrm{~m} / \mathrm{s}$ with an accuracy of $\pm 3 \%$ and a resolution of $0.1 \mathrm{~m} / \mathrm{s}$. Made up of a $490 \mathrm{MHz}-$ wireless data transmission module, microcontroller and power back, the wireless wind speed sensor sent wind speed data to the intelligent control focus node.

Portable anemoclinograph and digital hygrothermograph make up the environmental monitoring system. The former one was used to monitor and record wind speed and wind direction, while the latter one was to measure temperature and humidity.

Pollen collection slides, coated with vaseline, were fixed at the top of the tripod with a universal clamp as shown in Figure 2.

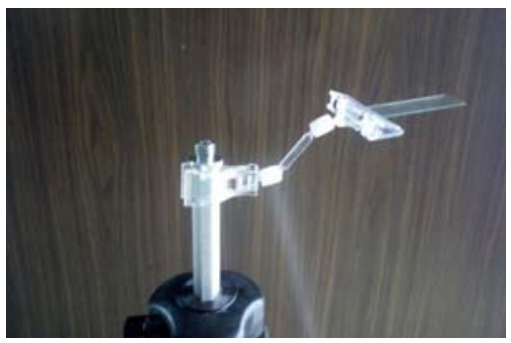

Figure 2 Pollen collection slides

\subsection{Test methods}

\subsubsection{Design of outdoor UAV's pollination tests}

According to the flowering period of rice, three tests were conducted from 11:00 a.m. to 12:00 a.m. at the hybrid rice seed production basis of Hunan Longping Seed Industry Co., Ltd. in Wugang County, Hunan Province. Following a row ratio of 6:60, the rice was transplanted by machines with plant spacing of $17 \mathrm{~cm} \times 14.5 \mathrm{~cm}$ and shares consistency in variety and growth condition. The rice to be tested was at its most luxuriant flowering period.

These outdoor tests were aimed to explore the distribution law of rice pollen under various influence factors at varying flight speeds. In reference to previous performance of UAV's pollination, agricultural UAV normally operates at 3-10 $\mathrm{m}$ above the canopy ${ }^{[15]}$ with an optimum flight speed of about $4 \mathrm{~m} / \mathrm{s}$. Another two speeds around the optimum speed were set. In other words, $3.5 \mathrm{~m} / \mathrm{s}, 4 \mathrm{~m} / \mathrm{s}$ and $4.5 \mathrm{~m} / \mathrm{s}$ were set as default speeds, at which the UAV flies across three separate sampling areas in sequence. Six rows of male parent rice in the middle serve as pollen supplier. Ten sampling nodes were regularly placed in a straight line on each side, vertical to the rows of male parent rice. The interval between every sampling node is $1 \mathrm{~m}$. From left to right, nodes are marked as $1 \#$ to $20 \#$ in order. Node $10 \#$ stands on the left side while node $11 \#$ on the right side of the male parent rice. Two neighboring sampling areas were separated by 6 rows of male parent rice that were not involved in pollination but to prevent the male parent rice in the middle of one test field from pollinating the adjoining female parent rice in the other area. Slides coated with vaseline were fixed above the rice canopy to collect male parent rice pollen at every sampling node. During the tests, the UVA flew across the 6 rows of male parent rice in the middle as Figure 3 presented.

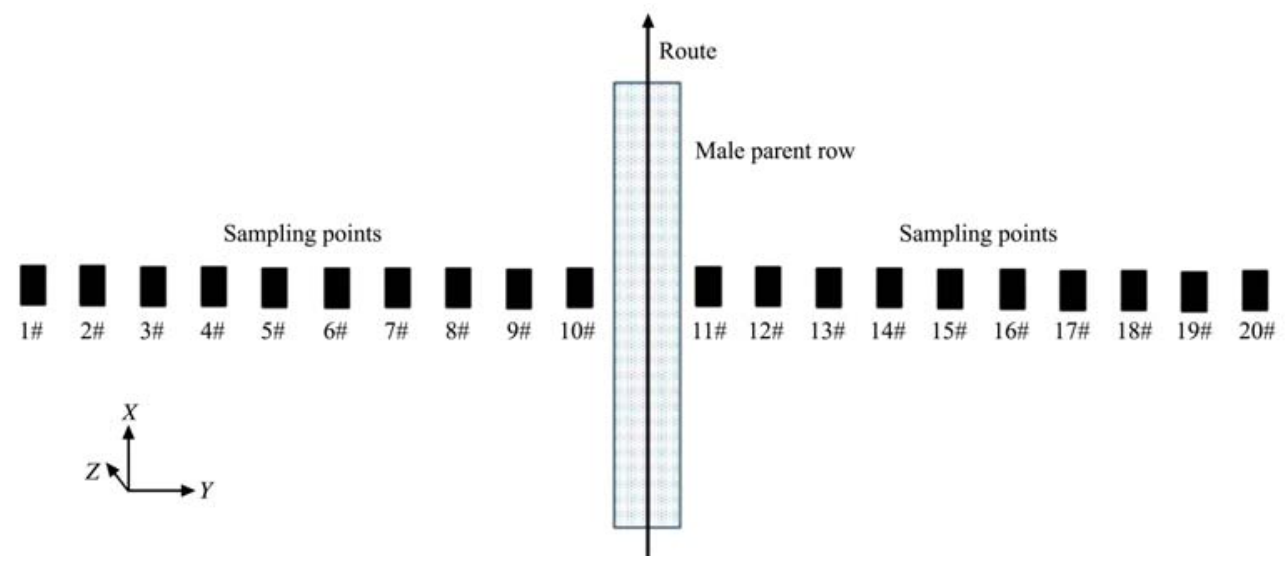

Figure 3 Schematic diagram of test 


\subsection{Data processing}

2.3.1 Acquisition of UAV's flight attitude parameters and meteorological parameters

Beidou Positioning System UB351 on-board the UAV acquires parameters like average flight altitude and average flight speed at three default speeds. Table 2 shows that meteorological parameters obtained from the environmental monitoring system.

\subsubsection{Coordinates of sampling nodes and UAV's route}

Beidou Positioning System UB351 positions sampling nodes and obtains their corresponding coordinates which are then used to map the position of collection points and the desired routes as Figure 3a describes.

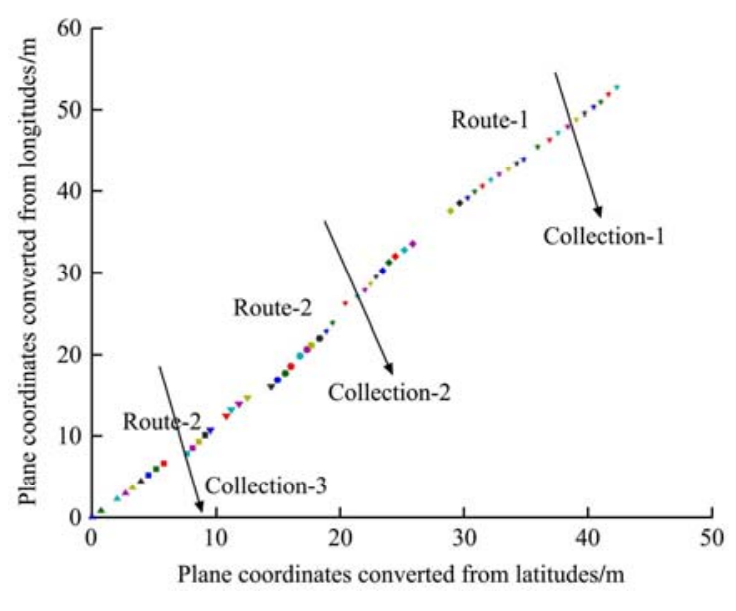

a. Position of collection points

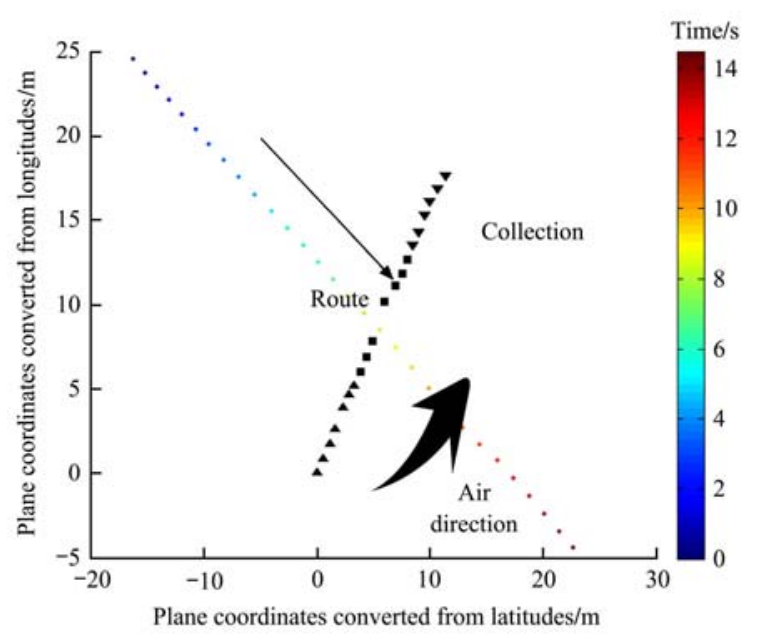

c. Trajectory of Test 2
Table 2 Flight attitude parameters of UAV

\begin{tabular}{lccc}
\hline \multirow{2}{*}{ Main Parameters } & \multicolumn{3}{c}{ Tests } \\
\cline { 2 - 4 } & 1 & 2 & 3 \\
\hline Average flight speed $/ \mathrm{m} \cdot \mathrm{s}^{-1}$ & 3.46 & 3.96 & 4.53 \\
Average flight altitude $/ \mathrm{m}$ & 1.23 & 1.33 & 1.15 \\
Average temperature $/{ }^{\circ} \mathrm{C}$ & & 33 & \\
Average humidity $/ \%$ & & 64 & 0 \\
Air speed $/ \mathrm{m}^{-1} \mathrm{~s}^{-1}$ & 0 & 0.3 & 0 \\
\hline
\end{tabular}

The mobile station of Beidou Positioning System UB351 on-board the UAV draws the trajectories of three tests. As shown in Table 2, the air speed in Test 1 and Test 3 is recorded $0 \mathrm{~m} / \mathrm{s}$ while that in Test 3 is $0.3 \mathrm{~m} / \mathrm{s}$. Figures 4b-4d respectively depict the final trajectory of every test.

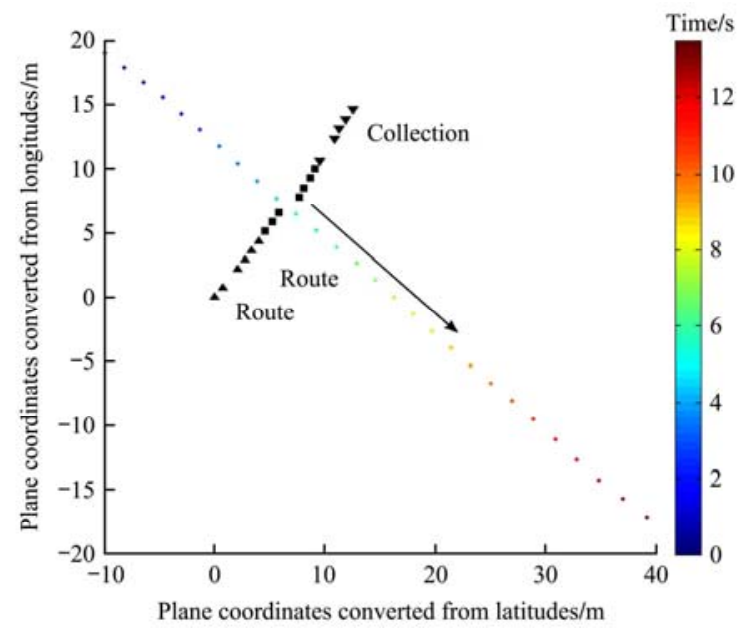

b. Trajectory of Test 1

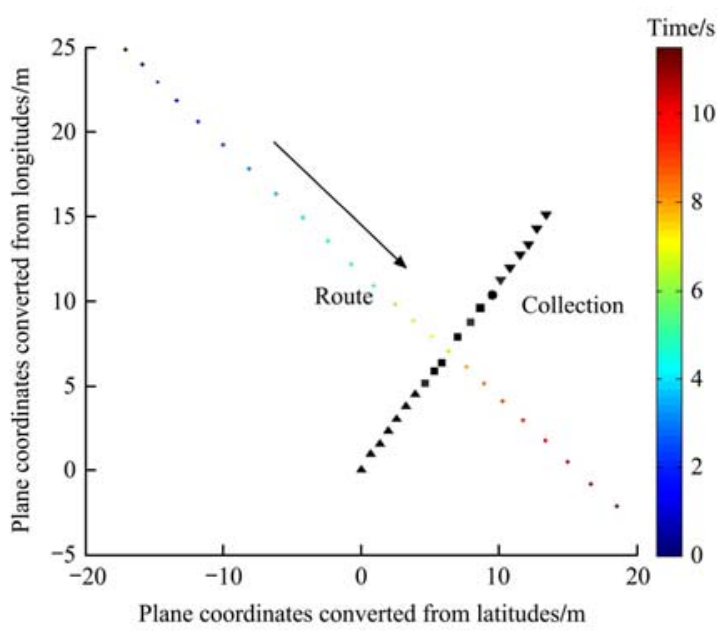

d. Trajectory of Test 3

Figure 4 Position of collection points and trajectory of test

\subsubsection{Acquisition and processing of wind field data}

On the basis of measurement of wind field of unmanned gasoline-driven helicopter ${ }^{[16]}$, three paddlewheel wind speed sensors are placed at every sampling node in the direction of $X, Y$ and $Z$ (longitudinal, lateral and vertical directions along with the flight route). Sampling nodes are marked from $1 \#$ to $20 \#$ in proper order. Consistent with the position and serial number of every sampling node, paddlewheel wind speed sensor measures three-direction speed at every point during 
UAV's pollination $^{[17,18]}$. Column chart is produced out of Excel as Figure 5 illustrates, where the abscissa represents the sampling nodes from 1 \# to 20\# while the ordinate indicates the wind speed in the direction of $X, Y$ and $Z$. The appropriate wind speed to study the wind field width is defined as the referential speed $(1 \mathrm{~m} / \mathrm{s})$ of pollen suspension ${ }^{[19,20]}$. Wind field width is the width covering all sampling nodes where the peak wind speeds respectively surpass $1 \mathrm{~m} / \mathrm{s}, 2 \mathrm{~m} / \mathrm{s}$ and $3 \mathrm{~m} / \mathrm{s}$. Table 3 shows three-direction peak wind speed, its corresponding sampling position and the wind field width corresponding to the referential speed interval in three tests.

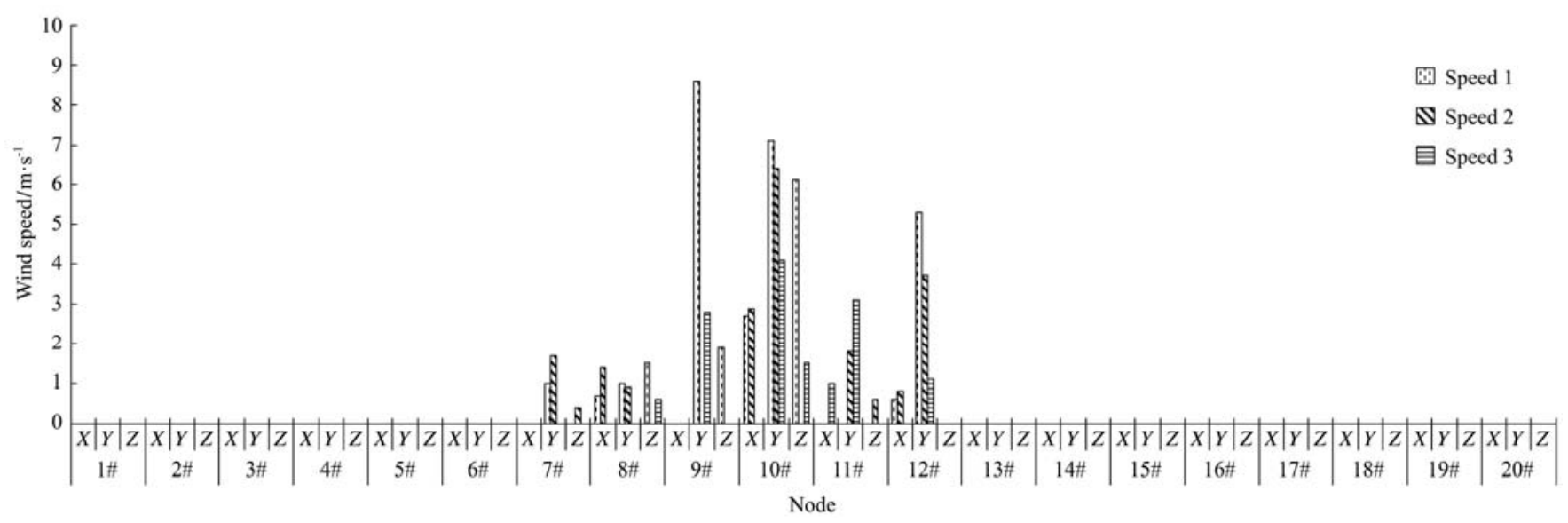

Figure 5 Wind speed produced by UAV

Table 3 Wind field test parameters of UAV

\begin{tabular}{|c|c|c|c|c|c|c|c|c|c|c|}
\hline \multirow{2}{*}{\multicolumn{2}{|c|}{ Main Parameters }} & \multicolumn{3}{|c|}{$X$} & \multicolumn{3}{|c|}{$Y$} & \multicolumn{3}{|c|}{$Z$} \\
\hline & & 1 & 2 & 3 & 1 & 2 & 3 & 1 & 2 & 3 \\
\hline \multicolumn{2}{|c|}{ Peak wind speed $/ \mathrm{m} \cdot \mathrm{s}^{-1}$} & 2.7 & 2.9 & 1.0 & 8.6 & 6.4 & 4.1 & 6.1 & 0.6 & 1.5 \\
\hline \multicolumn{2}{|c|}{ Sampling node corresponding to the peak/\# } & 10 & 10 & 11 & 9 & 10 & 10 & 10 & 11 & 10 \\
\hline \multirow[b]{2}{*}{ Wind field width $/ \mathrm{m}$} & $>1 \mathrm{~m} / \mathrm{s}$ & 1.26 & 0.67 & 0 & 5.81 & 4.16 & 3.73 & 3.17 & 0 & 0.67 \\
\hline & $>2 \mathrm{~m} / \mathrm{s}$ & 0.52 & 0.67 & 0 & 4.39 & 3.17 & 2.81 & 1.65 & 0 & 0 \\
\hline
\end{tabular}

\subsubsection{Pollen data acquisition and processing}

At the end of the tests, slides at 20 sampling nodes are collected. Five well-distributed club-like observation points on every slide are selected, dyed with iodine Potassium iodide and then placed under a $10 \times 10$ microscope. The eye lens is adjusted to fully examine every observation point and the pollen grains of three effective fields of view are counted. There are 15 effective fields on every slide in total, whose average pollen grains represents the overall pollen quantity of each slide.

\section{Results and analyses}

\subsection{Wind field distribution}

\subsubsection{Distribution of horizontal wind field}

The horizontal wind field formed by the wind from $X$-direction and $Y$-direction is at the same level of the rice canopy layer. The wind from these two directions is the main force for pneumatic conveying of pollen, and the stronger the wind is, the better it is ${ }^{[21]}$. As Table 3 shows, in terms of $Y$-direction wind speed among the three tests, the maximum wind field width of over $1 \mathrm{~m} / \mathrm{s}$ reaches $5.81 \mathrm{~m}$, while that of over $3 \mathrm{~m} / \mathrm{s}$ marks $4.09 \mathrm{~m}$. As for $X$-direction, the maximum width of over $1 \mathrm{~m} / \mathrm{s}$ is $1.26 \mathrm{~m}$; in the meanwhile, the $X$-direction speed of every sampling node is smaller than $3 \mathrm{~m} / \mathrm{s}$. This supports that the wind from $Y$-direction dominates the horizontal wind field and produces the widest wind field. Comparing the width of horizontal wind field of three tests reveals that the wind fields in Test 3 are the widest while those in Test 1 are the smallest. This is consistent with the conclusion from Li et al. ${ }^{[9]}$ that during multi-rotor electric UAV's pollination, wind field width is mainly influenced by UAV's flight speed and increases with the decrease of flight speed.

\subsubsection{Distribution of vertical wind field}

The vertical wind field formed by the wind from Z-direction is vertical to the rice canopy, where the 
wind's damage on the rice is studied and the weaker the wind is, the better it is ${ }^{[8]}$. It is learned from Table 4 that, of the three tests, node $10 \#$ and $11 \#$ boast peak wind speed in Z-direction. With a flight speed of $3.46 \mathrm{~m} / \mathrm{s}$, the peak wind speed in $Z$-direction reaches $6.1 \mathrm{~m} / \mathrm{s}$, contributing to the $3.1 \mathrm{~m}$ wide wind field of over $1 \mathrm{~m} / \mathrm{s}$. At the flight speed of $3.96 \mathrm{~m} / \mathrm{s}$, the peak wind speed in $Z$-direction drops to $0.6 \mathrm{~m} / \mathrm{s}$ when the wind speed of every sampling node is smaller than $1 \mathrm{~m} / \mathrm{s}$. With a flight speed of $4.53 \mathrm{~m} / \mathrm{s}$, the peak wind speed in Z-direction is $1.5 \mathrm{~m} / \mathrm{s}$ when no other nodes record a wind speed greater than $1 \mathrm{~m} / \mathrm{s}$ but 10\#. This indicates that flight speed obviously affects $Z$-direction wind speed, and that the flight speed of $3.96 \mathrm{~m} / \mathrm{s}$ produces the smallest vertical wind field. To sum up, when the UAV flies at $3.96 \mathrm{~m} / \mathrm{s}$, $Z$-direction wind field is favorable to pollination. To further investigate pollen distribution by taking both horizontal and vertical wind field into consideration, the pollen quantity at the sampling nodes undergoes statistical analysis.

\subsection{Pollen distribution}

Figure 6 depicts the pollen distribution of every sampling node, where the abscissa represents the sampling nodes from $1 \#$ to $20 \#$ with equal interval while the ordinate stands for their corresponding pollen quantity. As Figure 6 shows, node 10\# marks the peak value in three tests, and the pollen quantity decreases as the distance between node $7 \#$ to $12 \#$ and the row of male parent rice increases. The pollen quantity from node $1 \#$ to $7 \#$ and node $12 \#$ to $17 \#$ is small, fluctuating around 5 . Table 4 records the peak pollen quantity, corresponding sampling node, density of pollen, non-uniformity of pollen distribution ${ }^{[6]}$, distribution area ratio and distribution width. Pollen area ratio is the proportion of sampling nodes, whose pollen quantity exceeds a given quota, to the total number of sampling nodes. The analysis of pollen distribution width and area ratio in
Table 4 implies that, throughout three tests, the distribution width of more than 1 pollen grain basically agrees with the area ratio of more than 10 pollen grains. Varying flight speeds are proved to have little impact on the width of more than 1 and 10 pollen grains. Test 3 outweighs the other two with respect to distribution width and area ratio of over 5 pollen grains, while Test 1 basically agrees with Test 2 in these regards. The flight speed of $4.53 \mathrm{~m} / \mathrm{s}$ is believed to be influential to pollen distribution and the most favorable speed to pollen transmission. As Table 4 shows, pollen quantity of node $1 \#$ to $10 \#$ obviously outnumbers that of node $11 \#$ to $20 \#$, implying that UAV's wind filed exerts asymmetrical impact on pollen distribution.

In order to analyze the data model of pollen distribution, Q-Q plot of SPSS is employed for verification $^{[22]}$. In Figure 7 , the abscissa represents the observed value, the ordinate the expected normal value and the slope the standard deviation. The Figure reveals that the samples are not in straight-line distribution. Test of univariate normality is then conducted through Shapiro-Wilk test and Kolmogorov-Smimov test as shown in Table 5 with all Sig values smaller than 0.05. This indicates significant difference between pollen distribution and normal distribution, and supports that pollen distribution is against normal distribution ${ }^{[23]}$.

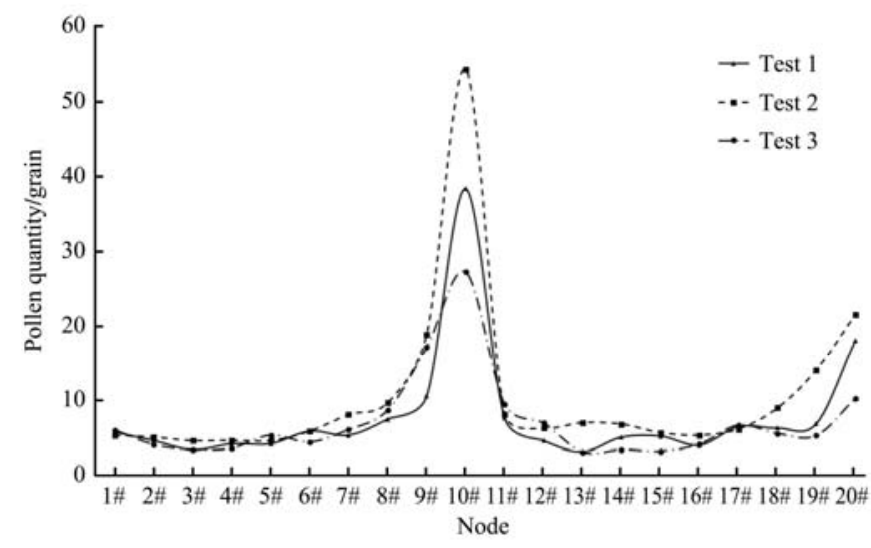

Figure 6 Pollen distribution of UAV's pollination

Table 4 Pollen distribution of UAV

\begin{tabular}{|c|c|c|c|c|c|c|c|c|c|c|c|c|}
\hline \multirow{2}{*}{ Tests } & \multirow{2}{*}{$\begin{array}{c}\text { Peak Pollen } \\
\text { quantity } \\
\text { /grain }\end{array}$} & \multirow{2}{*}{$\begin{array}{l}\text { Sampling node } \\
\text { corresponding to } \\
\text { the peak value/\# }\end{array}$} & \multirow{2}{*}{$\begin{array}{l}\text { Average } \\
\text { pollen } \\
\text { density }\end{array}$} & \multirow{2}{*}{$\begin{array}{l}\text { Non-uniformity } \\
\text { of pollen } \\
\text { distribution }\end{array}$} & \multicolumn{2}{|c|}{ Pollen quantity/grain } & \multicolumn{3}{|c|}{ Distribution area ratio/\% } & \multicolumn{3}{|c|}{ Distribution width/m } \\
\hline & & & & & $1 \#-10 \#$ & $11 \#-20 \#$ & $>1$ grain & $>5$ grains & $>10$ grains & $>1$ grain & $>5$ grains & $>10$ grains \\
\hline 1 & 38.3 & 10 & 7.9 & 7.9 & 90.3 & 67.9 & 100 & 65 & 15 & 18.13 & 8.46 & 1.07 \\
\hline 2 & 27.3 & 10 & 7.3 & 5.7 & 86.5 & 58.6 & 100 & 60 & 15 & 18.76 & 8.44 & 1.04 \\
\hline 3 & 54.1 & 10 & 10.6 & 11.3 & 121.4 & 90.5 & 100 & 85 & 20 & 18.36 & 14.57 & 1.83 \\
\hline
\end{tabular}



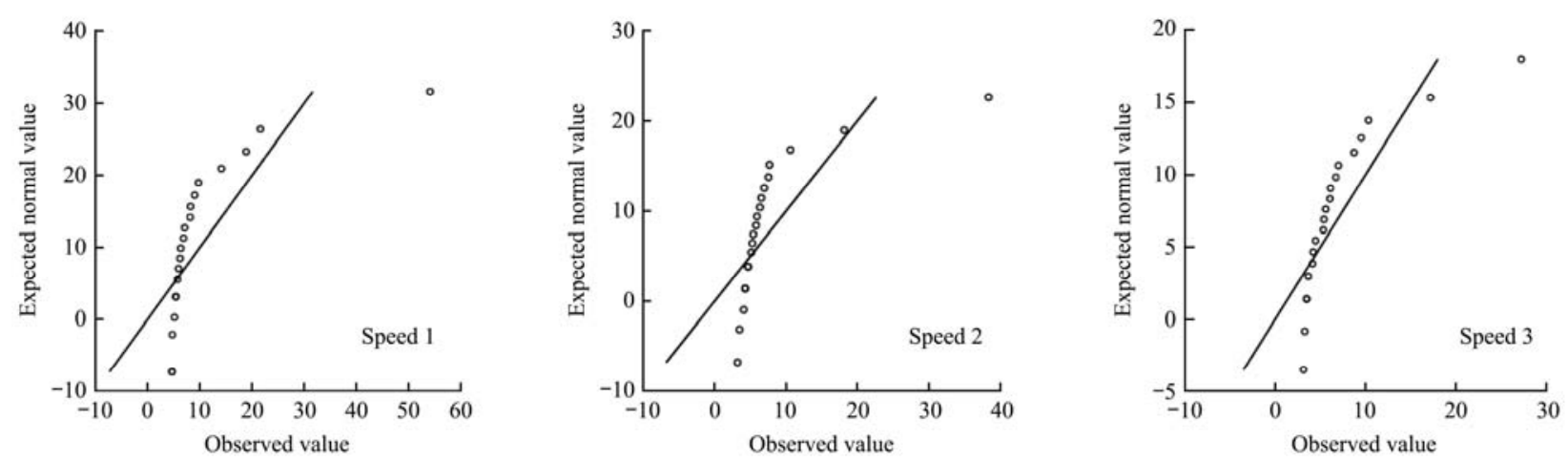

Figure 7 Q-Q plot test for UAV’s pollination

Table 5 Test of normality for pollen quantity

\begin{tabular}{cccccccc}
\hline \multirow{2}{*}{ Pollen quantity } & \multicolumn{3}{c}{ Kolmogorov-Smirnova test } & & \multicolumn{3}{c}{ Shapiro-Wilk test } \\
\cline { 2 - 7 } & Statistic & $d f$ & Sig. & Statistic & $d f$ & Sig. \\
\hline$m_{1}$ & 0.362 & 20 & 0 & 0.526 & 0.538 & 20 & 0 \\
$m_{2}$ & 0.331 & 20 & 0 & 0.671 & 20 & 0 \\
$m_{3}$ & 0.268 & 20 & 0.001 & & 0 \\
\hline
\end{tabular}

\subsection{Impact of wind field on pollen distribution}

The wind produced by the UAV acts on pollen in two forms, one on the stalk and the other on the pollens. The former one shakes the pollens off while the latter one blows the pollens off. Under the forces of three-direction wind, there are a series of complicated factors influencing pollen distribution. Therefore, wind speed in three directions and pollen quantity are categorized into five grades to reveal the relationship of wind field and pollen distribution, as shown in Table 6 .

According to the grades of wind speed and pollen quantity, a multiple linear regression model of pollen distribution and wind speed from three directions is established through SPSS, contributing to the ANOVA in Table 7.

\section{Table 6 Interval of wind speed and pollen quantity}

\begin{tabular}{ccccc}
\hline Grade & $\begin{array}{c}X \text {-direction } \\
\text { wind speed } \\
/ \mathrm{m} \cdot \mathrm{s}^{-1}\end{array}$ & $\begin{array}{c}Y \text {-direction } \\
\text { wind speed } \\
/ \mathrm{m}^{-1}\end{array}$ & $\begin{array}{c}Z \text {-direction } \\
\text { wind speed } \\
/ \mathrm{m}^{-1}\end{array}$ & $\begin{array}{c}\text { Pollen quantity } \\
\text { /grain }\end{array}$ \\
\hline 1 & $0-0.5$ & $0-1.5$ & $0-0.5$ & $0-10$ \\
2 & $0.5-1$ & $1.5-3$ & $0.5-1$ & $10-20$ \\
3 & $1-1.5$ & $3-4.5$ & $1-1.5$ & $20-30$ \\
4 & $1.5-2$ & $4.5-6$ & $1.5-2$ & $30-40$ \\
5 & $>2$ & $>6$ & $>2$ & $>40$ \\
\hline
\end{tabular}

Table 7 Multivariate linear regression analysis of UAV's pollination tests

\begin{tabular}{|c|c|c|c|c|c|c|c|c|}
\hline \multicolumn{7}{|c|}{ Coefficients } & \multicolumn{2}{|c|}{ ANOVA } \\
\hline \multirow{2}{*}{\multicolumn{2}{|c|}{ Model }} & Unstandardized & Coefficients & Standardized Coefficients & \multirow{2}{*}{$\mathrm{t}$} & \multirow{2}{*}{ Sig. } & \multirow{2}{*}{$F$ value } & \multirow{2}{*}{ Sig. } \\
\hline & & B value & Std. Error & Beta $(\beta)$ & & & & \\
\hline \multirow{4}{*}{ Test 1} & Constant & 0.340 & 0.146 & & 2.676 & 0.033 & \multirow{4}{*}{19.139} & \multirow{4}{*}{0} \\
\hline & $x_{1}$ & 0.379 & 0.141 & 0.488 & 0.644 & 0.017 & & \\
\hline & $y_{1}$ & -0.064 & 0.100 & 0.122 & 1.602 & 0.529 & & \\
\hline & $z_{1}$ & 0.219 & 0.137 & 0.351 & 2.359 & 0.129 & & \\
\hline \multirow{4}{*}{ Test 2} & Constant & 0.806 & 0.342 & & 2.618 & 0.031 & \multirow{4}{*}{9.256} & \multirow{4}{*}{0.001} \\
\hline & $x_{2}$ & 0.824 & 0.315 & 0.819 & 2.008 & 0.019 & & \\
\hline & $y_{2}$ & 0.582 & 0.290 & 0.582 & -2.111 & 0.062 & & \\
\hline & $z_{2}$ & -1.067 & 0.505 & -0.685 & 6.149 & 0.051 & & \\
\hline \multirow{4}{*}{ Test 3} & Constant & 2.138 & 0.348 & & 6.149 & 0 & \multirow{4}{*}{24.245} & \multirow{4}{*}{0} \\
\hline & $x_{3}$ & -2.032 & 0.364 & -0.869 & -5.587 & 0 & & \\
\hline & $y_{3}$ & 0.985 & 0.136 & 1.202 & 7.261 & 0.056 & & \\
\hline & $z_{3}$ & -0.028 & 0.104 & -0.034 & -0.269 & 0.792 & & \\
\hline
\end{tabular}

Table 7 includes constants, influence factors $\left(x_{n}, y_{\mathrm{n}}\right.$, $z_{n}$ ), standard error, Beta coefficient and $F$ value. $F$ value marks 19.139, 9.256 and 24.245 while the Sig values of regression equation are smaller than 0.05 , standing at $0.000,0.001$ and 0.000 , respectively. When the coefficients are not equal to 0 simultaneously, the 
explained variables share significant linear relation with the explanatory variables and a linear equation can be established. However, Table 7 shows that the significance levels in the directions of $X, Y$ and $Z$ are more than 0.05 throughout three tests, which means the equation of regression model is inapplicable to the study of wind speed grades in $Y$ and $Z$. As a result, a new model should be built. Backward screening is adopted to rebuild a model by successively skimming the wind grades in $Y$ and $Z$. Table 8 presents the linear regression analysis of $X$-direction in three tests.

Table 8 Linear regression analysis of UAV's pollination tests

\begin{tabular}{|c|c|c|c|c|c|c|}
\hline \multicolumn{7}{|c|}{ Coefficient } \\
\hline \multirow{2}{*}{\multicolumn{2}{|c|}{ Model }} & \multicolumn{2}{|c|}{$\begin{array}{l}\text { Unstandardized } \\
\text { Coefficients }\end{array}$} & \multirow{2}{*}{$\begin{array}{c}\begin{array}{c}\text { Standardized } \\
\text { Coefficients }\end{array} \\
\text { Beta }\end{array}$} & \multirow[t]{2}{*}{$t$ value } & \multirow[t]{2}{*}{ Sig. } \\
\hline & & $B$ value & Std. Error & & & \\
\hline \multirow{2}{*}{ Test 1} & Constant & 0.407 & 0.159 & & 2.564 & 0.020 \\
\hline & $x_{1}$ & 0.648 & 0.100 & 0.835 & 6.450 & 0 \\
\hline \multirow{2}{*}{ Test 2} & Constant & 0.439 & 0.278 & & 1.578 & 0.132 \\
\hline & $x_{2}$ & 0.712 & 0.168 & 0.707 & 4.239 & 0.000 \\
\hline \multirow{2}{*}{ Test 3} & Constant & 0.231 & 0.181 & & 1.274 & 0.219 \\
\hline & $x_{3}$ & 0.808 & 0.139 & 0.808 & 5.812 & 0 \\
\hline
\end{tabular}

In Table 8 , the average significant levels in $X$-direction of the three tests are equal to 0 , smaller than the standard value of 0.05 . So the wind speed grades in $X$-direction can be applied to the equation of regression model. Equations of linear regression model for three designated flight speeds are produced out of the constant coefficients and influence factors in Table 5 . Here are the Equations: $m_{1}=0.407+0.648 x_{1}, m_{2}=0.439+0.712 x_{2}$ and $m_{3}=0.231+0.808 x_{3} . \quad m_{1}, m_{2}$ and $m_{3}$ represent, respectively, the pollen grade of Tests 1,2 and 3 while $x_{1}, x_{2}$ and $x_{3}$ stand for the wind speed grade in $X$-direction of three tests. It can be concluded that pollen distribution is merely in positive linear relation with $X$-direction wind field, and that the coefficient scale of pollen grades and $X$-direction wind field varies as the flight speed differs.

\section{Conclusions}

The comparison and analysis of the wind field distribution, pollen distribution and pollen quantity under varying flight speeds contributes to the following conclusions:

After comparing the wind speed in $X$ and $Y$ direction, it is found that the wind from $Y$-direction dominates the horizontal wind field produced by rotor-wing UAV with the widest wind field. The contrast of the three-direction wind field width supports that flight speed mainly influences the wind field width. To be specific, horizontal wind field width decreases as the flight speed increases. The flight speed of $4.53 \mathrm{~m} / \mathrm{s}$ contributes to the maximum pollen distribution width and area ratio of more than 5 pollen grains, which is the most favorable speed to pollination. This also proves that pollen distribution is closely associated with both horizontal and vertical wind fields.

It is proved, through the comparison of pollen quantity from node $1 \#$ to $10 \#$ and $11 \#$ to $20 \#$, that the wind field produced by the rotor-wing UAV exerts asymmetrical impact on pollen distribution. Q-Q plot of SPSS verifies that pollen distribution is against normal distribution.

Three equations are figured out by building a multiple linear regression model of pollen distribution and wind speed scale from three directions. This demonstrates that pollen distribution is merely in positive linear relation with $X$-direction wind field, and that the coefficient scale of pollen grades and $X$-direction wind field varies as the flight speed differs.

\section{Acknowledgements}

This work was support by the grants of The National Key Research and Development Plan (2017YFD0701000), Guangdong National Natural Science Foundation of China (2015A030313420) and Agricultural standardization research project of Guangdong, China/2016. Sincere thanks goes to Yuan Long Ping High-Tech Agriculture Co., Ltd and Hi-Tech New Agriculture Technology Co., Ltd for their great contribution.

\section{[References]}

[1] Wu H, Xiong Z, Liu A M, Xiao C L, Tang Q Y. Research situation and proposals on supplementary pollination techniques in hybrid rice mechanized seed production. Crop Research, 2014; 28(3): 321-327. (in Chinese)

[2] Tang C Z, Wang H M, Li M, Li Z Q, Huang Z, Luo H F, et al. Study status and developmental strategies of mechanical 
pollination for hybrid rice breeding. Transactions of the CSAE, 2012; 28(4): 1-7. (in Chinese)

[3] Chang Z Y, Tu Y W. Studies on rice flowering and pollination habit. Jiangxi Journal of Agriculture, 1989; 1(2): 1-7. (in Chinese)

[4] Wang S H, Wang F Y, Wang L. Study on artificial pollination method for hybrid rice seed. Transactions of the CSAE, 2013; 10(232): 3-8. (in Chinese)

[5] Kempe K, Gils M. Pollination control technologies for hybrid breeding. Gils Mol Breeding, 2011; 27(4): 417-437.

[6] Li Z Q, Tang C Z, Li M, Luo H F. Pollen distribution of pneumatic and collision combined pollination for hybrid rice breeding. Journal of Hunan Agricultural University (Natural Sciences), 2015; 41(3): 325-331

[7] Wang H M. Experiment investigation of mechanism on pneumatic pollination of hybrid rice breeding. Hunan Changsha. Journal of Hunan Agricultural University, 2012. (in Chinese)

[8] Li J Y, Zhou Z Y, Hu L, Zang Y, Yan M L, Liu A M, et al. Optimization of operation parameters for supplementary pollination in hybrid rice breeding using uniaxial single-rotor electric unmanned helicopter. Transactions of the CSAE, 2014; 30(10): 10-17. (in Chinese)

[9] Li J Y, Zhou Z Y, Hu L, Zang Y, Xu S, Liu A M, et al. Optimization of operation parameters for supplementary pollination in hybrid rice breeding using round multi-axis multi-rotor electric unmanned helicopter. Transactions of the CSAE, 2014; 30(11): 1-9. (in Chinese)

[10] Li J Y, Zhou Z Y, Lan Y B, Hu L, Zang Y, Liu A M, et al. Distribution of canopy wind field produced by rotor unmanned aerial vehicle pollination operation. Transactions of the CSAE, 2015; 31(3): 77-86. (in Chinese)

[11] Hu L, Zhou Z Y, Luo X W, Wang P, Yan Y A, Li J Y. Development and experiment of a wireless wind speed sensor network measurement system for unmanned helicopter. Journal of Agricultural Machinery, 2014, 45(5): 221-226. (in Chinese)

[12] Wang H M, Tang C Z, Li M, Li Z Q, Huang Z, Wu M L, et al. Effect of airflow speed on pollen distribution for hybrid rice breeding pollination. Transactions of the CSAE, 2012, 28(6): 63-69. (in Chinese)
[13] Fang S L, Tang C Z, Luo H F. Effect of katabatic airflow velocity on the distribution of pollination of hybrid rice. Journal of Hunan Agricultural University (Natural Sciences), 2014; 40(4): 426-430. (in Chinese)

[14] Wu H. Research of effect on hybrid rice seed pollination with unmanned helicopter. Journal of Hunan Agricultural University, 2014. (in Chinese)

[15] Berni J A J, Zarco-Tejada P J, Sepulcre-Canto G, Fereres E, Villalobos F. Mapping canopy conductance and CWSI in olive orchards using high resolution thermal remote sensing imagery. Remote Sensing of Environment, 2009; 113(11): 2380-2388.

[16] Wang P, Hu L, Zhou Z Y, Yang W S, Liu A M, Luo X W, et al. Wind field measurement for supplementary pollination in hybrid rice breeding using unmanned gasoline engine single-rotor helicopter. Transactions of the CSAE, 2013, 29(3): 54-61. (in Chinese)

[17] Ao Z L, Li G S. Design and realization of automatic wind-speed sensor calibration system for automatic weather stations. Meteorological Science and Technology, 2007; 35(3): 429-431. (in Chinese)

[18] Zheng X W, Chen W K, Lü Y C. Realization of automatic control for wind speed sensor automatic calibration system. Meteorological Science and Technology, 2009; 37(2): 253-256. (in Chinese)

[19] $\mathrm{Hu}$ D M. Studies on the measurement and use of pollen suspended velocity in hybrid rice seed production. Hybrid Rice, 1996; 1: 11-13. (in Chinese)

[20] Hu D M. Distribution of pollen density and seed setting efficacy under different pollinating methods. Hybrid Rice, 1996; (6): 21-23. (in Chinese)

[21] Hu N, Chen W L, Liu S D, Luo W H, Zhao L L, Gao B. A model for simulating rice pollen dispersal. Acta Ecologica Sinica. 2010; 30(14): 3665-3671.

[22] Zong X P, Yao Y L. Quick test of the statistical distribution of data through Q-Q plot and P-P plot. Statistics \& Decision, 2010; 20: 151-152.

[23] Wang Z H, Zhou Q Z. Application and comparison of two methods for multivariate normality test. Journal of South-Central University for Nationalities (Nat. Sci. Edition). 2009; 28(3): 99-103. 